\title{
Effect of Nanoparticles Exposure on Fractional Exhaled Nitric Oxide (FENO) in Workers Exposed to Nanomaterials
}

\author{
Wei-Te Wu ${ }^{1, \dagger}$, Hui-Yi Liao ${ }^{1, \dagger}$, Yu-Teh Chung ${ }^{1}$, Wan-Fen Li ${ }^{2}$, Tsui-Chun Tsou ${ }^{1}$, Lih-Ann Li ${ }^{1}$, \\ Ming-Hsiu Lin ${ }^{3}$, Jiune-Jye Ho ${ }^{3}$, Trong-Neng Wu ${ }^{1,4}$ and Saou-Hsing Liou ${ }^{1,5,6, *}$
}

1 Division of Environmental Health and Occupational Medicine, National Health Research Institutes, Miaoli 350, Taiwan; E-Mails: ader.una@gmail.com (W.-T.W.); bobbibrownq@nhri.org.tw (H.-Y.L.); 010521@nhri.org.tw (Y.-T.C.); tctsou@nhri.org.tw (T.-C.T.); lihann@nhri.org.tw (L.-A.L.); tnwu@mail.cmu.edu.tw (T.-N.W.)

2 Division of Medical Genetics, Department of Medicine, University of Washington, Seattle, WA 98195, USA; E-Mail: wanfenli@u.washington.edu

3 Institute of Occupational Safety and Health, Council of Labor Affairs, Executive Yuan R.O.C., New Taipei 221, Taiwan; E-Mails: mhlin@mail.iosh.gov.tw (M.-H.L.);

hjj@mail.iosh.gov.tw (J.-J.H.)

4 Graduate Institute of Biostatistics, China Medical University, Taichung 402, Taiwan

5 Department of Public Health, National Defense Medical Center, Taipei 114, Taiwan

6 Department of Public Health, College of Public Health, China Medical University, Taichung 402, Taiwan

$\dagger$ These authors contributed equally to this work.

* Author to whom correspondence should be addressed; E-Mail: shliou@nhri.org.tw; Tel.: +886-37-246-166 (ext. 36500); Fax: +886-37-584-075.

Received: 11 December 2013; in revised form: 26 December 2013 / Accepted: 3 January 2014 / Published: 9 January 2014

\footnotetext{
Abstract: Fractional exhaled nitric oxide (FENO) measurement is a useful diagnostic test of airway inflammation. However, there have been few studies of FENO in workers exposed to nanomaterials. The purpose of this study was to examine the effect of nanoparticle (NP) exposure on FENO and to assess whether the FENO is increased in workers exposed to nanomaterials (NM). In this study, both exposed workers and non-exposed controls were recruited from NM handling plants in Taiwan. A total of 437 subjects (exposed group $=241$, non-exposed group $=196$ ) completed the FENO and spirometric measurements from 2009-2011. The authors used a control-banding (CB)
} 
matrix to categorize the risk level of each participant. In a multivariate linear regression analysis, this study found a significant association between risk level 2 of NP exposure and FENO. Furthermore, asthma, allergic rhinitis, peak expiratory flow rate (PEFR), and NF- $\kappa \mathrm{B}$ were also significantly associated with FENO. When the multivariate logistic regression model was adjusted for confounders, nano- $\mathrm{TiO}_{2}$ in all of the $\mathrm{NM}$ exposed categories had a significantly increased risk in FENO $>35 \mathrm{ppb}$. This study found associations between the risk level of NP exposure and FENO (particularly noteworthy for Nano- $\mathrm{TiO}_{2}$ ). Monitoring FENO in the lung could open up a window into the role nitric oxide (NO) may play in pathogenesis.

Keywords: nanoparticles; nanomaterials; workers's respiratory health; airway inflammation; Fractional exhaled nitric oxide; occupational epidemiology

\section{Introduction}

Many countries are currently supporting nanotechnology research and development for the production of nanomaterials (NM) due to the considerable economic potential of the technology. The market for NM is increasing rapidly and is predicted to have a \$3.1 trillion impact on the global economy by 2015 [1]. Although nanotechnology is applied to many different domains, engineered NM produced and handled in industrial and academic settings present new challenges in managing potential health risks to workers, consumers, and the environment [2,3]. Until now, however, most of the documents about the health hazards of nanoparticles (NP) have been provided mainly from animal or in vitro studies. The epidemiological data available on nanometric particles refer to environmental ultrafine particles (UFPs) while no data are available for NP exposed workers [4,5]. In most studies described above, these results suggested that UFP may be more toxic than particulate matter $(\mathrm{PM}) \leq 2.5$ and indicate an adverse relationship on cardiovascular and pulmonary morbidity and mortality; however, results are not consistent [4,5]. In addition, the physical and chemical characterization between engineered NP and ambient UFPs was totally different $[5,6]$, and it may lead to inconsistencies in health hazards.

Previous studies also showed that NP mainly deposit $(75 \%-80 \%)$ in the alveolar region where particles interfere with or within cells (like epithelial cells and macrophages) as well as with the mucus and clearance of NP from the lung, is slower than that of fine particles $(\mathrm{PM} \leq 2.5)$ [2,7-9]. Animal studies mentioned that the greater surface area per mass of NP is more active biologically than larger-sized particles with the same chemistry, and that particle surface area and number appear to be better predictors for NP-induced inflammatory and oxidative stress responses in the lung [9-11]. The number of workers who deal with NM is increasing rapidly; therefore, the validation methods to evaluate the inhalation toxicity of engineered NM in human are really needed.

The field of fractional exhaled nitric oxide (FENO) measurement has developed rapidly in recent decades. Measurement of FENO produced by the human lung and present in the exhaled breath is now recognized as a safe and useful diagnostic test of airway inflammation [12]. The European Respiratory Society (ERS) and the American Thoracic Society (ATS) have provided evidence that FENO is 
elevated in many lung diseases including asthma, atopy, upper airway viral infections, post-transplant lung rejection, radiation pneumonitis, and fibrosing alveolitis [12,13]. Furthermore, numerous studies have provided evidence regarding the applications of FENO in exposure assessment for epidemiologic studies [14,15]. Based on these studies, the results showed that the length of roads-traffic pollution - was positively associated with FENO in children with asthma [14], and that short-term increases in community-level ambient PM2.5 and PM10 were associated with elevated FENO [15]. To date, almost no research has been done on values and determinants of FENO in workers exposed to NM.

Therefore, the purpose of the study was to examine the effect of NP exposure on FENO and to investigate the determinants of increased FENO in workers exposed to NM.

\section{Results}

\subsection{Participant Characteristics and FENO Values}

Table 1 shows that FENO levels were significantly elevated in workers who were male, never smoked, and in the RL2 group. The results also found that workers who exercised $3 \mathrm{~h}$ before the tests had a decreased level in FENO (13.3 \pm 8.5 vs. $21.0 \pm 17.5$ ppb; $p=0.008)$. The FENO levels were compared between workers with and without different kinds of diseases; we found that workers with asthma or allergic rhinitis had significantly increased FENO compared to those without these diseases.

Table 1. Demographic characteristics and fractional exhaled nitric oxide (FENO) values of study participants $(n=437)$.

\begin{tabular}{|c|c|c|c|c|}
\hline \multirow{3}{*}{ Variables } & \multicolumn{4}{|c|}{ All subjects $(n=437)$} \\
\hline & \multicolumn{3}{|c|}{ Exhaled nitric oxide (ppb) } & \multirow[t]{2}{*}{$p$-Value ${ }^{a}$} \\
\hline & $n$ & Mean & $(\mathrm{SD})$ & \\
\hline Age & & & & 0.650 \\
\hline$\leq 40$ years & 317 & 20.7 & $(17.8)$ & \\
\hline$>40$ years & 120 & 20.2 & $(15.5)$ & \\
\hline Gender & & & & 0.011 \\
\hline Male & 300 & 21.7 & $(18.0)$ & \\
\hline Female & 137 & 18.0 & $(15.0)$ & \\
\hline Ethnic groups & & & & 0.084 \\
\hline Hoklo & 341 & 19.8 & $(15.9)$ & \\
\hline Hakka & 55 & 26.6 & $(25.6)$ & \\
\hline Others & 39 & 19.4 & $(12.1)$ & \\
\hline Education & & & & 0.253 \\
\hline$\leq$ Senior high and vocational school & 68 & 16.5 & $(8.6)$ & \\
\hline University and College & 206 & 21.3 & $(18.5)$ & \\
\hline$\geq$ Graduate School & 159 & 21.4 & (17.9) & \\
\hline Cigarette smoking & & & & 0.011 \\
\hline Current smokers & 66 & 15.5 & $(10.6)$ & \\
\hline Never smokers & 368 & 21.4 & $(17.9)$ & \\
\hline Alcohol use & & & & 0.998 \\
\hline Yes & 40 & 19.0 & $(12.2)$ & \\
\hline No & 396 & 20.8 & $(17.6)$ & \\
\hline
\end{tabular}


Table 1. Cont.

\begin{tabular}{|c|c|c|c|c|}
\hline \multirow{3}{*}{ Variables } & \multicolumn{4}{|c|}{ All subjects $(n=437)$} \\
\hline & \multicolumn{3}{|c|}{ Exhaled nitric oxide (ppb) } & \multirow[t]{2}{*}{$p$-Value ${ }^{2}$} \\
\hline & $n$ & Mean & $(\mathrm{SD})$ & \\
\hline Exercise before tests & & & & 0.008 \\
\hline Yes & 24 & 13.3 & $(8.5)$ & \\
\hline No & 410 & 21.0 & $(17.5)$ & \\
\hline Risk levels & & & & 0.040 \\
\hline Control & 196 & 20.5 & $(19.1)$ & \\
\hline Risk level 1 & 126 & 18.1 & $(12.2)$ & \\
\hline Risk level 2 & 115 & 23.3 & $(18.2)$ & \\
\hline Control and nanomaterial exposed groups & & & & 0.068 \\
\hline Control & 196 & 20.5 & $(19.1)$ & \\
\hline Carbon nanotube & 57 & 24.1 & $(18.7)$ & \\
\hline Nano- $\mathrm{TiO}_{2}$ & 17 & 28.0 & $(21.5)$ & \\
\hline Nano-SiO ${ }_{2}$ & 36 & 17.9 & $(10.8)$ & \\
\hline Nano-Ag & 16 & 20.8 & $(11.3)$ & \\
\hline Other NM exposure & 54 & 16.5 & $(10.6)$ & \\
\hline More than two types of NM exposure & 61 & 20.3 & $(16.3)$ & \\
\hline \multicolumn{5}{|l|}{ Disease History } \\
\hline Chronic bronchitis & & & & 0.139 \\
\hline Yes & 23 & 25.8 & $(20.1)$ & \\
\hline No & 412 & 20.3 & $(17.0)$ & \\
\hline Asthma & & & & $<0.001$ \\
\hline Yes & 9 & 58.7 & $(37.8)$ & \\
\hline No & 425 & 19.8 & $(15.6)$ & \\
\hline Allergic rhinitis & & & & $<0.001$ \\
\hline Yes & 80 & 27.1 & $(22.8)$ & \\
\hline No & 355 & 19.2 & $(15.4)$ & \\
\hline Atopic dermatitis & & & & 0.257 \\
\hline Yes & 27 & 24.2 & $(15.6)$ & \\
\hline No & 409 & 20.4 & $(17.3)$ & \\
\hline Hypertension & & & & 0.731 \\
\hline Yes & 31 & 19.1 & $(10.3)$ & \\
\hline No & 402 & 20.7 & $(17.7)$ & \\
\hline
\end{tabular}

${ }^{\mathrm{a}} t$-test to assess the difference in mean natural $\log (\ln )$-transformed FENO.

\subsection{Association of Determinants with FENO Values}

Significantly positive associations appeared between FENO and height $(r=0.098, p=0.041)$, body

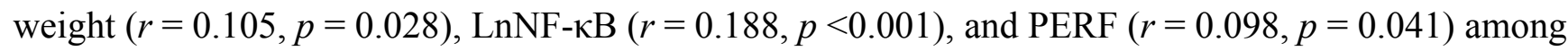
all participants (Table 2). 
Table 2. Correlation matrix of LnFENO, age, height, weight, LnNF- $\kappa B$, and Pulmonary function $(n=437)$.

\begin{tabular}{|c|c|c|c|c|c|}
\hline & LnFENO & Age (years) & Height (cm) & Weight (kg) & LnNF-кB (EBC) \\
\hline Age (years) & 0.033 & 1 & & & \\
\hline Height $(\mathrm{cm})$ & $0.098 *$ & $-0.231 * *$ & 1 & & \\
\hline Weight (kg) & $0.105 *$ & -0.083 & $0.631 * *$ & 1 & \\
\hline LnNF- $\kappa B(E B C)$ & $0.188 * *$ & 0.031 & $0.141 * *$ & $0.126 * *$ & 1 \\
\hline FEV1.0\% & 0.028 & $-0.240 * *$ & $-0.100 *$ & $-0.207 * *$ & -0.006 \\
\hline FVC (\%) & -0.048 & 0.000 & $0.141 * *$ & $0.117 *$ & -0.058 \\
\hline MMF (\%) & -0.021 & -0.052 & -0.086 & $-0.107 *$ & -0.059 \\
\hline PEFR (\%) & $0.098 *$ & 0.048 & -0.022 & 0.065 & -0.048 \\
\hline FEF25 (\%) & 0.056 & -0.005 & 0.021 & 0.082 & -0.048 \\
\hline FEF50 (\%) & -0.035 & -0.073 & -0.075 & -0.037 & -0.069 \\
\hline FEF75 (\%) & -0.036 & $-0.149 * *$ & 0.014 & $-0.138 * *$ & -0.046 \\
\hline FEV1/FVC & 0.012 & $0.285 * *$ & $-0.215 * *$ & $-0.168 * *$ & -0.061 \\
\hline
\end{tabular}

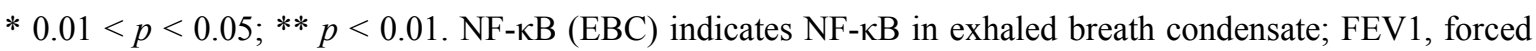
expiratory volume at 1 second; FVC, forced vital capacity; MMF, maximum mid-expiratory flow; PEFR, peak expiratory flow rate; FEF25, forced expiratory flow at 25\%; FEF50, forced expiratory flow at $50 \%$; FEF75, forced expiratory flow at 75\%; FEV1/FVC, the FEV1/FVC ratio.

After all variables were included in the multivariate regression analysis with the natural logarithm for FENO, we found that the NP exposed RL2 group had higher FENO levels than the control group (Table 3). Furthermore, cigarette smoking, exercise before tests, asthma, allergic rhinitis, PEFR (percentage), and NF-אB (EBC) were significant variables for FENO. Stepwise multiple regressions were used to choose the predictor variables carried out by the automatic procedure. This model presented the same significant variables for FENO except gender.

Table 3. Multiple linear regression model for determinants of fractional exhaled nitric oxide (FENO) values ${ }^{\text {a }}$.

\begin{tabular}{|c|c|c|c|c|c|c|}
\hline & \multicolumn{3}{|c|}{ Mode1 (Enter) } & \multicolumn{3}{|c|}{ Mode2 (Stepwise) } \\
\hline & $\boldsymbol{\beta}$ & SE & $p$-Value & $\beta$ & SE & $p$-Value \\
\hline Risk levels & & & & & & \\
\hline RL1 vs. control & -0.050 & 0.076 & 0.506 & -0.056 & 0.075 & 0.459 \\
\hline RL2 vs. control & 0.178 & 0.078 & 0.023 & 0.170 & 0.077 & 0.028 \\
\hline Age (years) & 0.006 & 0.004 & 0.143 & & & \\
\hline Gender (Male vs. Female) & 0.118 & 0.102 & 0.250 & 0.198 & 0.071 & 0.006 \\
\hline Height $(\mathrm{cm})$ & 0.006 & 0.006 & 0.327 & & & \\
\hline Weight $(\mathrm{kg})$ & 0.001 & 0.003 & 0.836 & & & \\
\hline Cigarette smoking (Yes vs. No) & -0.237 & 0.093 & 0.011 & -0.233 & 0.093 & 0.012 \\
\hline Exercise before tests (Yes vs. No) & -0.296 & 0.139 & 0.034 & -0.295 & 0.138 & 0.034 \\
\hline Asthma (Yes vs. No) & 1.020 & 0.236 & $<0.001$ & 1.042 & 0.222 & $<0.001$ \\
\hline Allergic rhinitis (Yes vs. No) & 0.289 & 0.081 & $<0.001$ & 0.289 & 0.080 & $<0.001$ \\
\hline PEFR $(\%)$ & 0.006 & 0.002 & 0.001 & 0.006 & 0.002 & 0.001 \\
\hline LnNF-kB (EBC) & 0.204 & 0.069 & 0.003 & 0.213 & 0.068 & 0.002 \\
\hline
\end{tabular}

${ }^{a}$ Using multiple linear regression models to relate natural $\log (\ln )$-transformed FENO. 
FENO values were further examined in different NM exposed categories. After adjusting for gender (male vs. female), cigarette smoking (yes vs. no), exercise before tests (yes vs. no), asthma (yes vs. no), allergic rhinitis (yes vs. no), LnNF-kB (EBC), and PEFR (\%), it was found that compared to the control group, Nano- $\mathrm{TiO}_{2}$ exposed group had significantly higher FENO levels, regardless of using the enter or stepwise methods (Table 4).

Table 4. Correlation of determinants of fractional exhaled nitric oxide (FENO) values in different nanomaterial exposed categories ${ }^{\mathrm{a}}$.

\begin{tabular}{|c|c|c|c|c|c|c|}
\hline & \multicolumn{3}{|c|}{ Mode1 (Enter) } & \multicolumn{3}{|c|}{ Mode2 (Stepwise) } \\
\hline & $\beta$ & SE & $p$-Value & $\boldsymbol{\beta}$ & SE & $p$-Value \\
\hline Nanomaterials exposure & & & & & & \\
\hline Carbon nanotube $v s$. control & 0.045 & 0.124 & 0.715 & 0.030 & 0.122 & 0.807 \\
\hline Nano- $\mathrm{TiO}_{2} v s$. control & 0.351 & 0.166 & 0.035 & 0.334 & 0.165 & 0.044 \\
\hline Nano- $\mathrm{SiO}_{2}$ vs. control & 0.007 & 0.120 & 0.956 & 0.022 & 0.119 & 0.857 \\
\hline Nano-Ag vs. control & 0.153 & 0.170 & 0.367 & 0.127 & 0.169 & 0.452 \\
\hline Other NM exposure vs. control & -0.039 & 0.100 & 0.695 & -0.049 & 0.100 & 0.623 \\
\hline More than two types of NM exposure $v s$. control & 0.051 & 0.098 & 0.600 & 0.052 & 0.097 & 0.591 \\
\hline Age (years) & 0.006 & 0.004 & 0.131 & & & \\
\hline Gender (Male vs. Female) & 0.099 & 0.104 & 0.342 & 0.182 & 0.073 & 0.013 \\
\hline Height $(\mathrm{cm})$ & 0.005 & 0.006 & 0.425 & & & \\
\hline Weight (kg) & 0.002 & 0.003 & 0.625 & & & \\
\hline Cigarette smoking (Yes vs. No) & -0.222 & 0.094 & 0.018 & -0.219 & 0.093 & 0.019 \\
\hline Exercise before tests (Yes vs. No) & -0.275 & 0.141 & 0.051 & -0.274 & 0.140 & 0.051 \\
\hline Asthma (Yes vs. No) & 1.008 & 0.239 & $<0.001$ & 1.053 & 0.225 & $<0.001$ \\
\hline Allergic rhinitis (Yes vs. No) & 0.289 & 0.082 & $<0.001$ & 0.290 & 0.081 & $<0.001$ \\
\hline PEFR $(\%)$ & 0.006 & 0.002 & 0.002 & 0.006 & 0.002 & 0.001 \\
\hline LnNF-кB (EBC) & 0.185 & 0.070 & 0.009 & 0.196 & 0.069 & 0.005 \\
\hline
\end{tabular}

${ }^{\mathrm{a}}$ Using multiple linear regression models to relate natural $\log (\ln )$-transformed FENO.

\subsection{Risk Levels in FENO Values}

In Figure 1, a multivariate logistic regression model was used to assess the association of risk levels in FENO values $>35 \mathrm{ppb}$ of all included subjects. When this model was adjusted for gender, cigarette smoking, exercise before tests, asthma, allergic rhinitis, NF- $\mathrm{BB}$ (EBC), and PEFR (\%), the RL2 group and the Nano- $\mathrm{TiO}_{2}$ exposure group showed significantly increased risk in FENO in comparison to the control group (AORs: 2.16 and 5.56; 95\% CI: 1.03-4.51 and 1.57-19.72, respectively). Similar associations for cigarette smoking, exercise before tests, asthma, allergic rhinitis, PEFR (percentage), LnNF- $\mathrm{kB}$ (EBC) were still observed in this model, although the data are not shown. Only $\mathrm{Nano}^{-\mathrm{TiO}_{2}}$ exposed and control groups $(n=213)$ were selected to calculate the risk in FENO $>35$ ppb in a multivariate logistic regression model that adjusted for the same variable. 
Figure 1. The odds ratio of risk levels (A) and by nanomaterials exposure (B) in fractional exhaled nitric oxide (FENO) values $>90$ th percentile $(35 \mathrm{ppb})$ of all 437 study subjects. [AOR: adjusted odds ratios for gender (male vs. female), cigarette smoking (yes vs. no), exercise before tests (yes vs. no), asthma (yes vs. no), allergic rhinitis (yes $v s$. no), LnNF-kB (EBC), and PEFR (\%)].

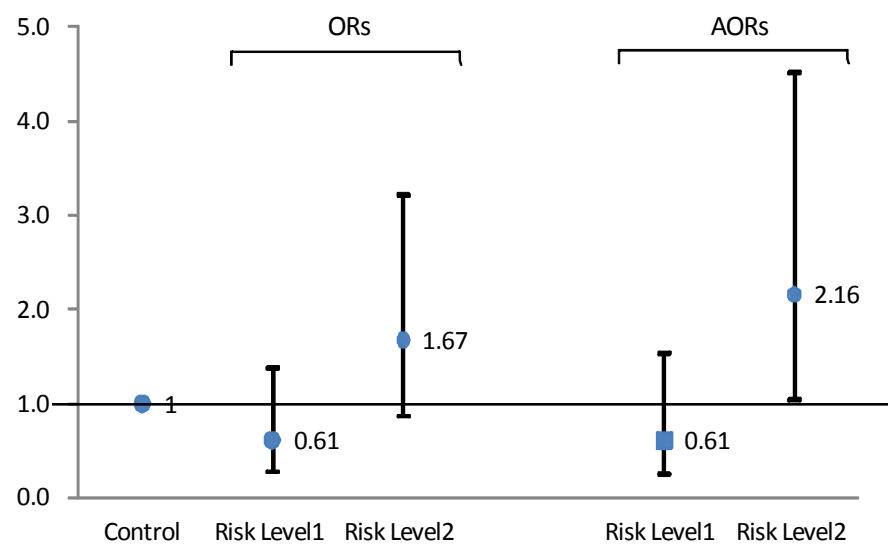

(A)

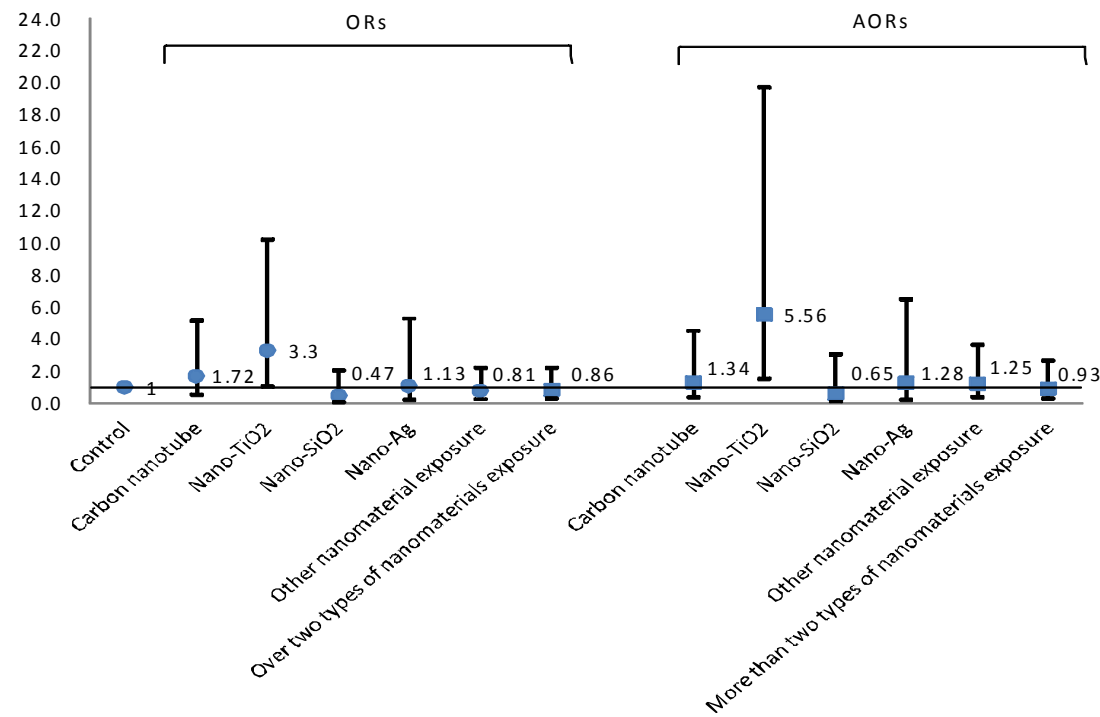

(B)

\section{Discussion}

For this study, the workers exposed to NM with a nano-tool risk level matrix greater than the second level had significantly higher FENO levels compared with the control group. In all of the NM exposed categories, nano- $\mathrm{TiO}_{2}$ was particularly noteworthy, because it had a significantly increased risk in FENO. Significant associations for FENO were also observed in such variables as gender, cigarette smoking, asthma, allergic rhinitis, replicating findings in other studies. Furthermore, the results also showed that NF- $\mathrm{BB}$ and PEFR were associated with increased FENO. 


\subsection{Inflammation and NOS2 Expression}

Inhalation of NP is the mechanism most widely researched and the interaction of NP with epithelial cells in the lungs is of interest. NP can be deposited in the respiratory tract, where they have been associated with oxidative stress related inflammatory reactions and damage to epithelial cells from reactive oxygen species and activation of regulation factors $[2,7,8,16]$. Nitric oxide (NO) is a gaseous signaling molecule that is generated by three isoenzymes of NO synthase (NOS) that are differentially regulated and expressed in the airways. The three isoenzymes of NOS also appear to play different pathophysiologic roles [13,17]. Among those, inducible NOS (NOS2) is constitutively expressed in the human airway epithelium, but its expression can be increased many times by inflammatory agents on macrophages. Furthermore, neuronal NOS (NOS1) and endothelial NOS (NOS3) are constitutively expressed enzymes in the lung that produce NO in low amounts and have an absolute requirement for intracellular calcium/calmodulin. The previous study showed that FENO variability is largely determined by epithelial NOS2 expression, with little contribution from other isoforms [18]. This study supports the hypothesis that NP enter in the respiratory tract where they produce inflammatory reactions to induce NOS2 expression that can be monitored in the exhaled breath.

\subsection{Different Nanomaterials (NM) Exposure and NOS Expression}

Until now, there has been little research of FENO in workers exposed to NM. According to past in vitro and in vivo studies, exposure to $\mathrm{TiO}_{2} \mathrm{NP}$ increases the $\mathrm{NO}$ in the mouse's brain after intragastric administration with $\mathrm{TiO}_{2} \mathrm{NP}$ for 60 consecutive days. After $\mathrm{TiO}_{2} \mathrm{NP}$ enter the mouse's brain, the excitatory neurotransmitter-Glu in the brains was significantly increased and the binding of Glu and NMDA receptors can activate calcium-dependent protease, i.e., NOS [19]. Another in vitro study showed that the NO production was only increased by exposure to $\mathrm{TiO}_{2} \mathrm{NP}$ in human umbilical vein endothelial cells (HUVECs), but the effect of the NO-dependent vasodilatory function was not observed [20]. Moreover, the increased NO content may arise from NOS2 activity, which has been upregulated in HUVECs during inflammation reactions. These three studies show that microvascular dysfunction associated with exposure to $\mathrm{TiO}_{2} \mathrm{NP}$ is not due to altered arteriolar smooth muscle responsiveness of $\mathrm{NO}$ [21-23], however they did not detect whether $\mathrm{TiO}_{2} \mathrm{NP}$ produced inflammatory reactions induce epithelial NOS2 expression.

Other NM exposure studies found that rat coronary endothelial cells exposed for $24 \mathrm{~h}$ to high doses of Ag NP (45 nm) $(100 \mu \mathrm{g} / \mathrm{mL})$ induce NO-dependent proliferation through activation of endothelial nitric oxide synthase (NOS3) [24], but this was not found at lower doses $(<10 \mu \mathrm{g} / \mathrm{mL})$. In another study, thirty days after exposure of silica NP $(600 \mu \mathrm{g} / \mathrm{rat})$, the results showed that pulmonary NOS2 was not enhanced in any of the evaluated endpoints [25]. In a study of iron oxide NP treatments in the human aortic endothelial cells (HAECs), the results showed that the NOS activity and NO levels were significantly elevated at relatively low doses of iron oxide $\mathrm{NP}\left(\mathrm{Fe}_{2} \mathrm{O}_{3}\right.$ and $\left.\mathrm{Fe}_{3} \mathrm{O}_{4}\right)$ [26], but the same result was not found in this study. 


\subsection{Determinants of Exhaled Nitric Oxide Levels (FENO)}

This study found that gender, cigarette smoking, asthma, and allergic rhinitis were significant variables for FENO. The ATS guidelines on the use of FENO mentioned that factors such as sex, asthma, atopy, and current cigarette smoking need to be taken into account when predicted values for FENO are derived from population-based reference equations [13,17]. Gender-related differences are biologically plausible as several in vitro studies have suggested that estrogen affects the expression of NOS [27], and therefore, may influence NO flux from the airway epithelium. In the majority of studies, FENO levels in males were higher than in females, when controlling for height, weight, lung function, smoking, atopy, asthma and rhinitis [17,28].

Previous studies also report that cigarette smoke decreases expression of inducible nitric oxide synthase (iNOS) and thus the interpretation of a FENO result obtained from a current smoker should be done with caution $[12,13,17,29,30]$. The possible explanation could be related to the smoking-induced high levels of exogenous NO and that this depends on a down-regulation of endogenous NO, such as NOS2 in lung epithelial cells and NOS3 in pulmonary artery endothelial cells [31-33]. Decreased endogenous NO may also be a result of reduced ciliary activity and local clearance from the airways [29]. Moreover, previous studies indicated that FENO levels increased in subjects after they quit smoking, but former smokers still had lower FENO levels compared with healthy control subjects [34,35]. The results showed that long-term cigarette smoking is associated with permanent reductions in FENO in smokers, even if they quit smoking.

Although the guideline of ATS mentioned that on the implementation of FENO it would seem prudent to avoid strenuous exercise before the measurement [36], the mechanism between exercise and FENO is still not clear. Our results regarding the effect of exercise on FENO are consistent with earlier studies [37,38]. As stated, these studies showed a drop in FENO values after exercise both in asthmatic and healthy children $[37,38]$. We thought that changes in bronchial diameter may be responsible for reduced FENO levels after exercise. The reduced airway surface area might have led to lower NO diffusion through the airways when using a constant exhalation flow during FENO measurements.

\subsection{NF- $\kappa B$ in Exhaled Breath Condensate}

Biomarkers in EBC can directly reflect airway inflammation and oxidative stress. In this study, the concentration of $\mathrm{NF}-\mathrm{\kappa B}$ in exhaled breath condensate was positively correlated with FENO. Previous studies showed an increased expression of NOS2 in airway epithelial cells, likely to be due to

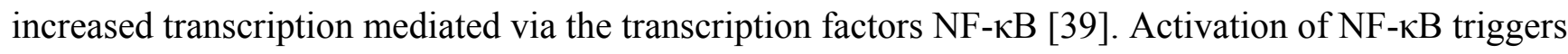
the expression of inflammatory cytokines. Consequently, polymorphonuclear leukocytes are attracted, activated, and result in NOS2 [39,40].

\subsection{Strengths and Limitations}

This study has several strengths. To the best of our knowledge, this study of the association between the many indicators of NM exposure and FENO in workers exposed to NM is the only one to date. Moreover, the authors adopted a comprehensive study design to validate the values and determinants of FENO among workers exposed to NM, in the ongoing occupational cohort study from 
14 NM-handling plants in Taiwan. The common determinants of FENO such as age, gender, height, atopy, variability in test time (the routine health check-up was taken in the morning), smoking, exercise before tests, and diet (fasting before routine health check-up) were considered.

There are some limitations to this study. First, a lack of personal sampling resulted in us being unable to analyze the realistic dose-response relationship. Workers involved in the handling of engineered nanomaterials are most probably exposed by inhalation; however, published information on exposures in the workplace is sparse. The main reason for this sparseness is that measuring exposure to engineered nanoparticles is not an easy task [41-45]. The behaviors and characteristics of engineered nanoparticles differ in several ways from traditional aerosols $[9,46]$. There is still insufficient scientific evidence to decide on which particle size range and exposure parameters of engineered nanoparticles should be measured to characterize exposure, or which are the most appropriate instruments or methods to be used [41-45]. Faced with uncertainties relating to nanomaterial exposure assessment, control banding principles have recently become popular [47,48]. With the control banding approach, hazard (severity) bands are generated based on toxicologic data of nanomaterials combined with exposure (probability) bands reflecting the exposure levels. Control banding is a semi-quantitative assessment of the risk that offers the minimal preventive measures to be implemented according to the estimated level of risk. Second, the heterogeneity of NM made it difficult to find a sufficiently large group of workers exposed to the same particles and to present potential health effects of any one NM. In spite of this, this study still found that only workers exposed to nano- $\mathrm{TiO}_{2}$ had a significant increase in FENO. Thirdly, genetic polymorphisms of NOS may be related to FENO levels, but until now the results have been inconsistent.

\section{Subjects and Methods}

\subsection{Study Subjects and Data Collection}

We conducted a survey of the nanotechnology plants in Taiwan. According to the lists of NM handling plants from the Environmental Health and Safety project, this study excluded some which were selling only, but not handling raw NM, some which were shut-down, or had never used NM, or were not currently using NM. The basic information on these factories that agreed to participate in this study is listed in Table S1. Among these 13 factories, five factories manufactured NM and 12 factories applied NP to manufacture other products. The physico-chemical properties of NM manufactured and/or used in these factories are listed in Table S2. These factories hired 515 workers from 2009-2011, and the participation rate in this study was 89\% (458/515).

The judgment of exposed workers and non-exposed controls was based on an industrial hygienist and supervisor in each factory. To ensure correct classification, we also requested workers and the company to provide NM category, size and amount in the handle process. The collection of the above information had been added in Table S3. The non-exposed controls were selected from workers at the same plants as the exposed workers, but who did not handle NM. Two hundred and fifty eight workers exposed to NM and 200 non-exposed controls were recruited to take part in this study from 2009-2011. The Institutional Review Board of National Health Research Institutes, Miaoli, Taiwan, approved this study. Informed consent was obtained from each of the subjects after a detailed 
explanation of the nature and possible consequences of the study by the interviewer on the day of personal interview. After a written informed consent was obtained from individual participants, the subjects were interviewed in person using a structured questionnaire and health examinations. FENO measurements were taken, spirometry was conducted, and each person was interviewed using a structured questionnaire. Information was collected on age, gender, exercise, smoking and alcohol consumption, history of disease, NM handling, and exposure probability at the workplace.

FENO measurements were performed on workers when they received their routine health check-up on one morning per year. Lung function measurements were taken after the FENO measurement. For each participant, the authors also collected exhaled breath condensate (EBC) and stored it at $-80{ }^{\circ} \mathrm{C}$,

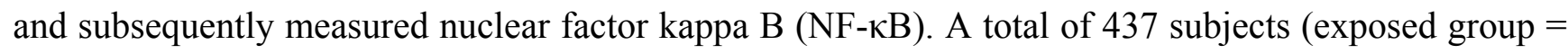
241 , non-exposed group $=196)$ completed the measurements. The complete examination rate was $95 \%$.

\subsection{Fractional Exhaled Nitric Oxide (FENO) and Pulmonary Function Measurement}

A chemiluminescence analyzer (Bedfont Scientific, Kent, UK) was used according to current guidelines of the ATS/ERS to measure FENO. The chemiluminescence analyzer process was repeated at least three times to ensure reproducibility (correlation coefficient is $0.960, p<0.001$ ). Exhalation time for each subject was $12 \mathrm{~s}$ with a flow of $50 \mathrm{~mL} / \mathrm{s}$.

Subjects tested with the computerized spirometer (Chest graph HI-701, Chest M.I. Inc. Hongo, Bunkyo-Ku-Tokyo, Japan). The spirometer directly enters age, gender, height, and race, in order to calculate the predicted normal lung function value and to determine the percentage of the predicted value. The spirometer calibration check was performed by a 3-liter-calibration pump before each testing session. The lung function parameters examined forced expiratory volume at $1 \mathrm{~s}$ (FEV1), forced vital capacity (FVC), maximum mid-expiratory flow (MMF), peak expiratory flow rate (PEFR), the FEV1/FVC ratio, and forced expiratory flow (FEF) between $25 \%$ and $75 \%$ of FVC.

\subsection{Exhaled Breath Condensate (EBC) Collection}

EBC samples were collected during the 15 minutes of tidal breathing by using a single-use disposable collecting circuit (DECCS 04 ST, Medivac, Parma, Italy) with an ECoScreen Turbo (VIASYS Healthcare GmbH, Hoechberg, Germany). The temperature of $-6{ }^{\circ} \mathrm{C}$ was constantly maintained during the collection. $\mathrm{EBC}$ samples were stored at $-80{ }^{\circ} \mathrm{C}$ in polypropylene tubes until assayed.

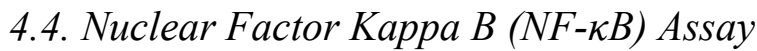

The luciferase reporter assays (inflammatory response reporter array) were used to detect the activation of inflammatory response transcription factors. HL-CZ cells were cultured overnight on 96 well plate (total volume $=50 \mu \mathrm{L}$ cell suspension/well, $1 \times 10^{4}$ cells/well in triplicate). Then to every well was added $50 \mu \mathrm{L}$ pAC NF- $\mathrm{BB}(\mathrm{MOI}=0.2)$ for $16 \mathrm{~h}, 100 \mu \mathrm{L}$ TNF- $\alpha(200 \mathrm{pg} / \mathrm{mL})$ and $10 \mu \mathrm{L}$ EBC sample for $6 \mathrm{~h}$ of incubation. Cell lysates were collected using $60 \mu \mathrm{L}$ of lysis buffer (0.1 M KH2PO4, pH 7.9, 0.5\% Triton X-100, 1 mM DTT). Luciferase activity was measured by standard protocols [49]. 


\subsection{Exposure Assessment}

Methods for measuring occupational exposure need to be developed in order to identify and monitor hazards associated with NP exposure and to provide workers with recommendations for reducing exposures $[4,5,41,50,51]$. However, there is still no standardized method of monitoring exposure to $\mathrm{NM}$ in the field of occupational health. Only limited research into monitoring of exposure has been conducted due to the instrument barrier [44,45,52-55], and many real-world results have shown the levels of exposure to be likely transient or very low.

In such a context of uncertainty in exposure assessment, the control banding (CB) approach may be helpful in implementing a risk-management strategy according to a precautionary approach. Recently, worldwide several CB approaches for manufactured NM-related exposure have been developed and published [47,56-61]. Despite limitations, in the absence of occupational exposure limits (OELs), CB may be a useful strategy for assessing and controlling occupational hazards as part of a comprehensive safety and health program [61].

In this study, the CB nano-tool risk level matrix proposed by Dr. Paik and his colleagues was used to categorize the risk level of each participant [47]. We used the latest version of "CB Nanotool 2.0" [62]. Briefly, the risk level matrix was calculated based on the severity score of the NM toxicity and the score of the exposure probability. The factors considered in the calculation of the severity score included NM ( $70 \%$ of severity score) and parent material (30\% of severity score). In order to obtain consistent scores, the NM toxicity severity score was based on the summary tables from the review document. The exposure probability score was based on the questionnaires collected from individual workers exposed to the various NM. The cross-table of the severity scores and probability scores were used to generate the risk levels (RLs, 1-4) for each individual. The higher the risk level, the higher the severity of NM toxicity and/or the higher the exposure probability. The detailed information of the summary of the most important characteristics of probability scores, severity factors and scores, and CB nano-tool risk level matrix are presented in Tables S4 and S5. The comparison with the classification of the different NPs in terms of Risk levels are shown in Table S6.

\subsection{Statistical Analysis}

The FENO and NF- $\mathrm{BB}$ exhibited right-skewed distributions. Therefore the natural logarithmic transformation was applied. Means and standard deviations were used to describe the distributions of continuous variables. The Student's $t$-test and analysis of variance were used to test the differences among risk variables. Pearson's correlation analysis was used to measure the association for continuous variables. A linear regression model and a logistic regression model were used to compare the FENO between different risk level (RL) workers and the controls, based on the risk levels categorized from the CB method mentioned above. The workers were divided into seven groups depending on whether the workers handled and used NM in the workplace: (1) control group; (2) carbon nanotube exposed group; (3) nano- $\mathrm{TiO}_{2}$ exposed group; (4) nano- $\mathrm{SiO}_{2}$ exposed group; (5) nano-Ag exposed group; (6) other NM exposed group; and (7) more than two types of NM exposed group. Based on the published literature [63,64], these studies suggested that a FENO value greater than 35 ppb was predictive of poor asthma control. Moreover, FENO levels of $<35 \mathrm{ppb}$ are accepted as normal values 
for healthy adults when measured by standard methods in different populations [65]. In our study subjects, the 90th percentiles of FENO values also were $35 \mathrm{ppb}$. Thus we selected $35 \mathrm{ppb}$ as a cutoff point for high and low NO in this study. The statistical analyses were performed using SPSS, version 19.0 for Windows. All statistical tests were two-sided with $p<0.05$ as the level of statistical significance.

\section{Conclusions}

Until recently, scientists had little information regarding the health hazards of NP exposure. Employee medical surveillance is a strategy for providing benefits to the individual and company for health outcomes for workers exposed to NM. Among the health checkups, FENO might be a useful indicator of broader epithelial function in addition to being an inflammatory marker for workers potentially exposed to NP, although this aspect requires more investigation. Therefore, monitoring FENO in the lung could open up a window into the role NO may play in pathogenesis.

\section{Acknowledgments}

This study was partly supported by National Health Research Institutes (98A1-EOSP03-014, 99A1-EOSP03-014, 00A1-EOSP03-014, 01A1-EOSP03-014) and Institute of Occupational Safety and Health (IOSH98-M323, IOSH99-M323, IOSH100-M323, IOSH101-M323), Taiwan, ROC. The authors thank CJ Tsai at National Chiao-Tung University, Taiwan, ROC, and M. Ellenbecker and Candace SJ Tsai at the University of Massachusetts, Lowell, MA, USA for their assistance in the exposure assessments of NP in the workplace. The authors thank all the study participants.

\section{Conflicts of Interest}

The authors declare no conflict of interest.

\section{References}

1. Schmidt, C.W. Nanotechnology-related environment, health, and safety research: Examining the national strategy. Environ. Health Perspect 2009, 117, A158-A161.

2. Stebounova, L.V.; Morgan, H.; Grassian, V.H.; Brenner, S. Health and safety implications of occupational exposure to engineered nanomaterials. Wiley Interdiscip. Rev. Nanomed. Nanobiotechnol. 2012, 4, 310-321.

3. Maynard, A.D.; Aitken, R.J.; Butz, T.; Colvin, V.; Donaldson, K.; Oberdorster, G.; Philbert, M.A.; Ryan, J.; Seaton, A.; Stone, V.; et al. Safe handling of nanotechnology. Nature 2006, 444, 267-269.

4. Peters, A.; Ruckerl, R.; Cyrys, J. Lessons from air pollution epidemiology for studies of engineered nanomaterials. J. Occup. Environ. Med. 2011, 53, S8-S13.

5. Eisen, E.A.; Costello, S.; Chevrier, J.; Picciotto, S. Epidemiologic challenges for studies of occupational exposure to engineered nanoparticles; a commentary. J. Occup. Environ. Med. 2011, 53, S57-S61.

6. Donaldson, K.; Stone, V.; Tran, C.L.; Kreyling, W.; Borm, P.J. Nanotoxicology. Occup. Environ. Med. 2004, 61, 727-728. 
7. Nanoparticle Task Force ACOEM. Nanotechnology and health. J. Occup. Environ. Med. 2011, 53, 687-689.

8. Moller, W.; Felten, K.; Meyer, G.; Meyer, P.; Seitz, J.; Kreyling, W.G. Corrections in dose assessment of $99 \mathrm{mTc}$ radiolabeled aerosol particles targeted to central human airways using planar gamma camera imaging. J. Aerosol. Med. Pulm. Drug Deliv. 2009, 22, 45-54.

9. Oberdorster, G.; Oberdorster, E.; Oberdorster, J. Nanotoxicology: An emerging discipline evolving from studies of ultrafine particles. Environ. Health Perspect. 2005, 113, 823-839.

10. Brown, D.M.; Wilson, M.R.; MacNee, W.; Stone, V.; Donaldson, K. Size-dependent proinflammatory effects of ultrafine polystyrene particles: A role for surface area and oxidative stress in the enhanced activity of ultrafines. Toxicol. Appl. Pharmacol. 2001, 175, 191-199.

11. Oberdorster, G. Pulmonary effects of inhaled ultrafine particles. Int. Arch. Occup. Environ. Health 2001, 74, 1-8.

12. ATS Workshop Proceedings: Exhaled nitric oxide and nitric oxide oxidative metabolism in exhaled breath condensate: Executive summary. Am. J. Respir. Crit. Care Med. 2006, 173, 811-813.

13. Dweik, R.A.; Boggs, P.B.; Erzurum, S.C.; Irvin, C.G.; Leigh, M.W.; Lundberg, J.O.; Olin, A.C.; Plummer, A.L.; Taylor, D.R. An official ATS clinical practice guideline: Interpretation of exhaled nitric oxide levels (FENO) for clinical applications. Am. J. Respir. Crit. Care Med. 2011, 184, 602-615.

14. Eckel, S.P.; Berhane, K.; Salam, M.T.; Rappaport, E.B.; Linn, W.S.; Bastain, T.M.; Zhang, Y.; Lurmann, F.; Avol, E.L.; Gilliland, F.D. Residential traffic-related pollution exposures and exhaled nitric oxide in the children's health study. Environ. Health Perspect. 2011, 119, 1472-1477.

15. Berhane, K.; Zhang, Y.; Linn, W.S.; Rappaport, E.B.; Bastain, T.M.; Salam, M.T.; Islam, T.; Lurmann, F.; Gilliland, F.D. The effect of ambient air pollution on exhaled nitric oxide in the Children's Health Study. Eur. Respir. J. 2011, 37, 1029-1036.

16. Knol, A.B.; de Hartog, J.J.; Boogaard, H.; Slottje, P.; van der Sluijs, J.P.; Lebret, E.; Cassee, F.R.; Wardekker, J.A.; Ayres, J.G.; Borm, P.J.; et al. Expert elicitation on ultrafine particles: Likelihood of health effects and causal pathways. Part. Fibre Toxicol. 2009, 6, 19.

17. Barnes, P.J.; Dweik, R.A.; Gelb, A.F.; Gibson, P.G.; George, S.C.; Grasemann, H.; Pavord, I.D.; Ratjen, F.; Silkoff, P.E.; Taylor, D.R.; et al. Exhaled nitric oxide in pulmonary diseases: A comprehensive review. Chest 2010, 138, 682-692.

18. Lane, C.; Knight, D.; Burgess, S.; Franklin, P.; Horak, F.; Legg, J.; Moeller, A.; Stick, S. Epithelial inducible nitric oxide synthase activity is the major determinant of nitric oxide concentration in exhaled breath. Thorax 2004, 59, 757-760.

19. Hu, R.; Gong, X.; Duan, Y.; Li, N.; Che, Y.; Cui, Y.; Zhou, M.; Liu, C.; Wang, H.; Hong, F. Neurotoxicological effects and the impairment of spatial recognition memory in mice caused by exposure to TiO2 nanoparticles. Biomaterials 2010, 31, 8043-8050.

20. Mikkelsen, L.; Sheykhzade, M.; Jensen, K.A.; Saber, A.T.; Jacobsen, N.R.; Vogel, U.; Wallin, H.; Loft, S.; Moller, P. Modest effect on plaque progression and vasodilatory function in atherosclerosis-prone mice exposed to nanosized TiO(2). Part. Fibre Toxicol. 2011, 8, 32. 
21. Nurkiewicz, T.R.; Porter, D.W.; Hubbs, A.F.; Stone, S.; Chen, B.T.; Frazer, D.G.; Boegehold, M.A.; Castranova, V. Pulmonary nanoparticle exposure disrupts systemic microvascular nitric oxide signaling. Toxicol. Sci. 2009, 110, 191-203.

22. LeBlanc, A.J.; Moseley, A.M.; Chen, B.T.; Frazer, D.; Castranova, V.; Nurkiewicz, T.R. Nanoparticle inhalation impairs coronary microvascular reactivity via a local reactive oxygen species-dependent mechanism. Cardiovasc. Toxicol. 2010, 10, 27-36.

23. LeBlanc, A.J.; Cumpston, J.L.; Chen, B.T.; Frazer, D.; Castranova, V.; Nurkiewicz, T.R. Nanoparticle inhalation impairs endothelium-dependent vasodilation in subepicardial arterioles. J. Toxic. Environ. Health A 2009, 72, 1576-1584.

24. Rosas-Hernandez, H.; Jimenez-Badillo, S.; Martinez-Cuevas, P.P.; Gracia-Espino, E.; Terrones, H.; Terrones, M.; Hussain, S.M.; Ali, S.F.; Gonzalez, C. Effects of 45-nm silver nanoparticles on coronary endothelial cells and isolated rat aortic rings. Toxicol. Lett. 2009, 191, 305-313.

25. Coccini, T.; Roda, E.; Barni, S.; Signorini, C.; Manzo, L. Long-lasting oxidative pulmonary insult in rat after intratracheal instillation of silica nanoparticles doped with cadmium. Toxicology 2012, $302,203-211$.

26. Zhu, M.T.; Wang, B.; Wang, Y.; Yuan, L.; Wang, H.J.; Wang, M.; Ouyang, H.; Chai, Z.F.; Feng, W.Y.; Zhao, Y.L. Endothelial dysfunction and inflammation induced by iron oxide nanoparticle exposure: Risk factors for early atherosclerosis. Toxicol. Lett. 2011, 203, 162-171.

27. Weiner, C.P.; Knowles, R.G.; Moncada, S. Induction of nitric oxide synthases early in pregnancy. Am. J. Obstet. Gynecol. 1994, 171, 838-843.

28. Liu, H.C.; Hsu, J.Y.; Cheng, Y.W.; Chou, M.C. Exhaled nitric oxide in a Taiwanese population: Age and lung function as predicting factors. J. Formos. Med. Assoc. 2009, 108, 772-777.

29. Balint, B.; Donnelly, L.E.; Hanazawa, T.; Kharitonov, S.A.; Barnes, P.J. Increased nitric oxide metabolites in exhaled breath condensate after exposure to tobacco smoke. Thorax 2001, 56, 456-461.

30. Olin, A.C.; Rosengren, A.; Thelle, D.S.; Lissner, L.; Bake, B.; Toren, K. Height, age, and atopy are associated with fraction of exhaled nitric oxide in a large adult general population sample. Chest 2006, 130, 1319-1325.

31. Hoyt, J.C.; Robbins, R.A.; Habib, M.; Springall, D.R.; Buttery, L.D.; Polak, J.M.; Barnes, P.J. Cigarette smoke decreases inducible nitric oxide synthase in lung epithelial cells. Exp. Lung Res. 2003, 29, 17-28.

32. Wei, X.M.; Kim, H.S.; Kumar, R.K.; Heywood, G.J.; Hunt, J.E.; McNeil, H.P.; Thomas, P.S. Effects of cigarette smoke on degranulation and NO production by mast cells and epithelial cells. Respir. Res. 2005, 6, 108.

33. Su, Y.; Han, W.; Giraldo, C.; de Li, Y.; Block, E.R. Effect of cigarette smoke extract on nitric oxide synthase in pulmonary artery endothelial cells. Am. J. Respir. Cell Mol. Biol. 1998, 19, 819-825.

34. Robbins, R.A.; Millatmal, T.; Lassi, K.; Rennard, S.; Daughton, D. Smoking cessation is associated with an increase in exhaled nitric oxide. Chest 1997, 112, 313-318.

35. Hogman, M.; Holmkvist, T.; Walinder, R.; Merilainen, P.; Ludviksdottir, D.; Hakansson, L.; Hedenstrom, H. Increased nitric oxide elimination from the airways after smoking cessation. Clin. Sci. 2002, 103, 15-19. 
36. ATS/ERS recommendations for standardized procedures for the online and offline measurement of exhaled lower respiratory nitric oxide and nasal nitric oxide, 2005. Am. J. Respir. Crit. Care Med. 2005, 171, 912-930.

37. Gabriele, C.; Pijnenburg, M.W.; Monti, F.; Hop, W.; Bakker, M.E.; de Jongste, J.C. The effect of spirometry and exercise on exhaled nitric oxide in asthmatic children. Pediatr. Allergy Immunol. 2005, 16, 243-247.

38. Persson, M.G.; Wiklund, N.P.; Gustafsson, L.E. Endogenous nitric oxide in single exhalations and the change during exercise. Am. Rev. Respir. Dis. 1993, 148, 1210-1214.

39. Xie, Q.W.; Kashiwabara, Y.; Nathan, C. Role of transcription factor NF-kappa B/Rel in induction of nitric oxide synthase. J. Biol. Chem. 1994, 269, 4705-4708.

40. Kharitonov, S.A.; Barnes, P.J. Exhaled markers of pulmonary disease. Am. J. Respir. Crit. Care Med. 2001, 163, 1693-1722.

41. Riediker, M.; Schubauer-Berigan, M.K.; Brouwer, D.H.; Nelissen, I.; Koppen, G.; Frijns, E.; Clark, K.A.; Hoeck, J.; Liou, S.H.; Ho, S.F.; et al. A road map toward a globally harmonized approach for occupational health surveillance and epidemiology in nanomaterial workers. J. Occup. Environ. Med. 2012, 54, 1214-1223.

42. Brouwer, D. Exposure to manufactured nanoparticles in different workplaces. Toxicology 2010, 269, 120-127.

43. Brouwer, D.; Berges, M.; Virji, M.A.; Fransman, W.; Bello, D.; Hodson, L.; Gabriel, S.; Tielemans, E. Harmonization of measurement strategies for exposure to manufactured nano-objects; report of a workshop. Ann. Occup. Hyg. 2012, 56, 1-9.

44. Dahm, M.M.; Evans, D.E.; Schubauer-Berigan, M.K.; Birch, M.E.; Fernback, J.E. Occupational exposure assessment in carbon nanotube and nanofiber primary and secondary manufacturers. Ann. Occup. Hyg. 2012, 56, 542-556.

45. Kuhlbusch, T.A.; Asbach, C.; Fissan, H.; Gohler, D.; Stintz, M. Nanoparticle exposure at nanotechnology workplaces: A review. Part. Fibre Toxicol. 2011, 8, 22.

46. Borm, P.J.; Robbins, D.; Haubold, S.; Kuhlbusch, T.; Fissan, H.; Donaldson, K.; Schins, R.; Stone, V.; Kreyling, W.; Lademann, J.; et al. The potential risks of nanomaterials: A review carried out for ECETOC. Part. Fibre Toxicol. 2006, 3, 11.

47. Paik, S.Y.; Zalk, D.M.; Swuste, P. Application of a pilot control banding tool for risk level assessment and control of nanoparticle exposures. Ann. Occup. Hyg. 2008, 52, 419-428.

48. Brouwer, D.H. Control banding approaches for nanomaterials. Ann. Occup. Hyg. 2012, 56, 506-514.

49. Sambrook, J.; Russell, D.W. Assay for luciferase in extracts of Mammalian cells. CSH Protoc. 2006, doi:10.1101/pdb.prot3642.

50. Schulte, P.A.; Schubauer-Berigan, M.K.; Mayweather, C.; Geraci, C.L.; Zumwalde, R.; McKernan, J.L. Issues in the development of epidemiologic studies of workers exposed to engineered nanoparticles. J. Occup. Environ. Med. 2009, 51, 323-335.

51. Laney, A.S.; McCauley, L.A.; Schubauer-Berigan, M.K. Workshop summary: Epidemiologic design strategies for studies of nanomaterial workers. J. Occup. Environ. Med. 2011, 53, S87-S90.

52. Methner, M.; Hodson, L.; Dames, A.; Geraci, C. Nanoparticle Emission Assessment Technique (NEAT) for the identification and measurement of potential inhalation exposure to engineered nanomaterials_-Part B: Results from 12 field studies. J. Occup.Environ. Hyg. 2010, 7, 163-176. 
53. Demou, E.; Stark, W.J.; Hellweg, S. Particle emission and exposure during nanoparticle synthesis in research laboratories. Ann. Occup. Hyg. 2009, 53, 829-838.

54. Demou, E.; Peter, P.; Hellweg, S. Exposure to manufactured nanostructured particles in an industrial pilot plant. Ann. Occup. Hyg. 2008, 52, 695-706.

55. Dahm, M.M.; Evans, D.E.; Schubauer-Berigan, M.K.; Birch, M.E.; Deddens, J.A. Occupational exposure assessment in carbon nanotube and nanofiber primary and secondary manufacturers: Mobile direct-reading sampling. Ann. Occup. Hyg. 2013, 57, 328-344.

56. Zalk, D.M.; Paik, S.Y.; Swuste, P. Evaluating the control banding nanotool: A qualitative risk assessment method for controlling nanoparticle exposures. J. Nanopart. Res. 2009, 11, 1685-1704.

57. Van Duuren-Stuurman, B.; Vink, S.R.; Verbist, K.J.; Heussen, H.G.; Brouwer, D.H.; Kroese, D.E.; van Niftrik, M.F.; Tielemans, E.; Fransman, W. Stoffenmanager Nano version 1.0: A web-based tool for risk prioritization of airborne manufactured nano objects. Ann. Occup. Hyg. 2012, 56, 525-541.

58. Ostiguy, C.; Riediker, M.; Triolet, J.; Troisfontaines, P.; Vernez, D. Development of a Specific Control Banding Tool for Nanomaterials; French Agency for Food, Environmental and Occupational Health and Safety: Maisons-Alfort, France, 2010.

59. Riediker, M.; Ostiguy, C.; Triolet, J.; Troisfontaine, P.; Vernez, D.; Bourdel, G.; Thieriet, N.; Cadène, A. Development of a control banding tool for nanomaterials. J. Nanomater. 2012, 2012, doi:10.1155/2012/879671.

60. Höck, J.; Epprecht, T.; Furrer, E.; Hofmann, H.; Höhner, K.; Krug, H.; Lorenz, C.; Limbach, L.; Gehr, P.; Nowack, B.; et al. Precautionary Matrix for Synthetic Nanomaterials; Federal Office of Public Health FOPH: Berne, Switzerland, 2011.

61. National Institute for Occupational Safety and Health, Education and Information Division; American Industrial Hygiene Association, Risk Assessment, Committee. Qualitative Risk Characterization and Management of Occupational Hazards: Control Banding (CB)_Literature Review and Critical Analysis; National Institute for Occupational Health and Safety: Cincinnati, $\mathrm{OH}, \mathrm{USA}, 2009$.

62. CB Nanotool 2.0. Available online: http://www.controlbanding.net/Services.html (accessed on 16 March 2010).

63. Smith, A.D.; Cowan, J.O.; Brassett, K.P.; Herbison, G.P.; Taylor, D.R. Use of exhaled nitric oxide measurements to guide treatment in chronic asthma. N. Engl. J. Med. 2005, 352, 2163-2173.

64. Dweik, R.A.; Sorkness, R.L.; Wenzel, S.; Hammel, J.; Curran-Everett, D.; Comhair, S.A.; Bleecker, E.; Busse, W.; Calhoun, W.J.; Castro, M.; et al. Use of exhaled nitric oxide measurement to identify a reactive, at-risk phenotype among patients with asthma. Am. J. Respir. Crit. Care Med. 2010, 181, 1033-1041.

65. Bora, M.; Alpaydin, A.O.; Yorgancioglu, A.; Akkas, G.; Isisag, A.; Coskun, A.S.; Celik, P. Does asthma control as assessed by the asthma control test reflect airway inflammation? Multidiscip. Respir. Med. 2011, 6, 291-298.

(C) 2014 by the authors; licensee MDPI, Basel, Switzerland. This article is an open access article distributed under the terms and conditions of the Creative Commons Attribution license (http://creativecommons.org/licenses/by/3.0/). 